\title{
Teología y pastoral de la vocación en el contexto actual
}

\section{Theology and Pastoral of Vocation in the Present-Day Context}

Nicolás Álvarez de las Asturias

Universidad Eclesiástica San Dámaso

Madrid. España

ID ORCID 0000-0003-3630-3516

nalvarez@sandamaso.es

Resumen: Reflexionar sobre cómo acompañar a los jóvenes en el descubrimiento de su propia vocación, es uno de los objetivos principales de la próxima Asamblea del Sínodo de los Obispos, prevista para octubre de 2018. En el presente artículo se reflexiona sobre la comprensión teológica actual de la vocación, ofreciendo algunas claves pastorales, para que ésta pueda ser percibida, acogida y vivida como una «buena noticia» en las circunstancias actuales.

Palabras clave: Vocación, Acompañamiento espiritual, Pastoral vocacional, Discernimiento.
Abstract: Pondering over ways of accompanying young people in their vocational discernment is one of the principal aims of the upcoming Assembly of the Synod of Bishops scheduled in October 2018. This article offers some pastoral keys and reflects on the current theological understanding of vocation. It seeks to make vocation perceived, welcomed, and lived as «good news» in the contemporary world.

Keywords: Vocation, Spiritual Accompaniment, Pastoral for Fostering Vocation, Discernment. 
$\ll A$ nunciar la alegría del Evangelio es la misión que el Señor ha confiado a su Iglesia... La Iglesia ha decidido interrogarse sobre cómo acompañar a los jóvenes para que reconozcan y acojan la llamada al amor y la vida en plenitud» ${ }^{1}$. Con estas palabras introduce el Documento preparatorio el objetivo de la próxima asamblea ordinaria del Sínodo de los Obispos. Por ello, si se quiere contribuir a la reflexión solicitada por el Santo Padre, resultará necesario, en primer lugar, reflexionar sobre qué es la vocación y cómo explicarla de un modo comprensible y fecundo para los jóvenes de hoy. Sólo en dicha reflexión podrá fundarse un intento de propuesta de acción pastoral en el campo del discernimiento y acompañamiento de las vocaciones, objeto principal de este trabajo.

\section{LA VOCACIÓN Y EL EVANGELIO DE LA VOCACIÓN \\ EN EL CONTEXTO ACTUAL}

\section{Vocación como categoría teológica fundamental}

En cierto sentido, puede afirmarse que la palabra vocación es polisémica desde el punto de vista teológico. Se refiere, en efecto, primeramente a una realidad universal, que tiene su fundamento en la voluntad salvífica de Dios y que hace, por tanto, a cada hombre su interlocutor, llamándole, en la Iglesia, a la santidad y al apostolado.

Pero, a la vez, por vocación entendemos el designio particular, singular e irrepetible de Dios por cada hombre, que es expresión de su amor y que constituye, desde el punto de vista del hombre, la luz que ilumina el sentido de su existencia, situándole de un modo concreto en y ante la Iglesia y el mundo. Es de esta segunda acepción de la que se ocupará la próxima asamblea sinodal y, por tanto, también este estudio.

Estas dos grandes acepciones de la palabra «vocación» encuentran su fundamento en la Sagrada Escritura, cuyas enseñanzas al respecto son la fuen-

1 SínOdo de los Obispos, Los jóvenes, la fe y el discernimiento vocacional. Documento preparatorio (13I-2017), Introducción. El documento no tiene numeración interna, por lo que se citará en adelante como Documento preparatorio, y la indicación de la parte, el capítulo y el epígrafe para facilitar la búsqueda del texto citado. 
te principal de toda reflexión teológica al respecto, pero también de toda acción pastoral ${ }^{2}$.

Por otra parte, cada época histórica ha encontrado su propio modo de explicar la vocación, partiendo de su propia comprensión de la Escritura y de los acentos en los que se percibía importante incidir en la pastoral vocacional $^{3}$. En este sentido, considero que el presente contexto teológico y eclesial obliga a presentar la teología de la vocación a partir de dos coordenadas principales: la comprensión de la relación entre el hombre y Dios en clave de diálogo -y de diálogo en la Iglesia-, y a la luz de la condición histórica del hombre, que lleva necesariamente a una comprensión dinámica de la vocación.

\section{a) Carácter dialógico y eclesial}

Como se sabe, el Concilio Vaticano II describió la Revelación de Dios como un diálogo con los hombres, no únicamente para comunicar conocimientos sino, principalmente, «para invitarlos a la comunión consigo y recibirlos en su compañía» ${ }^{4}$. En este contexto dialógico debe encuadrarse la reflexión teológica sobre la vocación al menos por dos razones principales ${ }^{5}$.

La primera es el dato bíblico, que es el alma de la teología. En la Escritura, antes que «reflexión sobre la vocación» hay «relatos de vocación»; narraciones que presentan la intervención de Dios en la vida de determinados hombres en orden a una misión precisa, y la respuesta de éstos. Y tan importante es este modo de actuar de Dios, que le da su propio Nombre. Dios, en

\footnotetext{
${ }^{2}$ La bibliografía al respecto es numerosísima. Vid. como síntesis LÉGASSE, S., «Vocation. I. Écriture Sainte», en Dictionnaire de Spiritualitè 16, 1081-1092; MARTINI, C. M. y VANHOYE, A., La llamada en la Biblia, Madrid: Atenas, 1983. Cfr. Francisco, Discurso al Congreso internacional de pastoral vocacional (21-X-2016), que es en realidad una lectio divina del relato de la vocación de Mateo, haciendo derivar así toda la acción pastoral de la Iglesia de la meditación y contemplación de la Palabra de Dios.

3 Vid. al respecto, SAuvage, M., «Vocation. II. Des vocations particulières: sacerdoce et vie consacrée», en Dictionnaire de Spiritualitè 16, 1102. En las columnas anteriores, aporta citas de distintos teólogos que parten de la predestinación, encuadrándolos en los desafíos pastorales de su momento histórico. Cfr. también IZARD, R., «L'évolution de la notion de vocation dans l'histoire», Vocation 255 (1971) 299-319. Sobre la renovación de la teología de la vocación sacerdotal en el último siglo, cfr. DE La LAMA, E., La vocación sacerdotal. Cien años de clarificación, Madrid: Palabra, 1994. Por último, vid. un completo planteamiento sistemático en Illanes, J. L., Tratado de teología espiritual, Pamplona: Eunsa, 2007, 155-187.

4 Cfr. Concilio Vaticano II, Const. Dog. Dei Verbum, 2.

${ }^{5} \mathrm{Y}$, de hecho, así lo hace el magisterio postconciliar, como puede verse en S. JUAN Pablo II, Ex. Ap. Pastores dabo vobis (25-III-1992), 36 (en adelante: PDV).
} 
efecto, se presenta a sí mismo como «el Dios de Abraham, el Dios de Isaac y el Dios de Jacob» $(\operatorname{Ex~} 3,6)^{6}$ y, en la plenitud de su Revelación, como «el Dios y Padre de nuestro Señor Jesucristo» (Ef 1,3), que «revela al hombre al propio hombre y le descubre la sublimidad de su vocación» ${ }^{7}$. En este sentido, se puede afirmar que el hecho de la vocación ilumina y en cierto modo revela el verdadero Rostro de Dios (un Dios que llama), pero también que ilumina el sentido profundo de la vida del hombre, que sólo puede ser percibida a la luz de Cristo.

La segunda razón es porque la vocación como categoría antropológica y teológica incluye la respuesta libre del hombre. Sólo cuando se da dicha respuesta puede hablarse de vocación en sentido pleno, puesto que sólo entonces empieza a realizarse. Por eso ha podido decirse, con razón, que la respuesta configura la llamada ${ }^{8}$.

Ahora bien, entender así la vocación, significa entenderla como el encuentro entre el designio de Dios y la libertad del hombre en un clima de libertad. Dios llama a la puerta del corazón del hombre para, con él, construir su historia. Ni por parte de Dios ni por parte del hombre nos encontramos ante algo estático 9 . Por eso, desde el punto de vista antropológico, la gran pregunta es: cómo puede el hombre responder libremente a la invitación gratuita y amorosa de $\operatorname{Dios}^{10}$. No es una cuestión sencilla y no será poco apuntar algunos elementos que ayuden a encontrar una respuesta.

En primer lugar, la respuesta pasa necesariamente por crear las condiciones para que la vocación pueda entenderse en términos de libertad. Libertad, en primer lugar, de cualquier tipo de coacción externa. Pero, sobre todo, de libertad como capacidad de elección y, más radicalmente aún, como capacidad de autodeterminación y de adhesión.

En efecto, para el pleno desarrollo de la vocación, no basta la libertad de, sino que resulta imprescindible la libertad para, en su sentido más profundo: el que trasciende la posibilidad de optar entre cuestiones más o menos bana-

${ }^{6}$ Cfr. RAtzinger, J., Introducción al cristianismo, Salamanca: Sígueme, 1987, 90 y 95-98.

7 Cfr. Concilio Vaticano II, Const. Past. Gaudium et Spes, 22.

8 «La respuesta a la propia vocación, en cualquier caso, no es sólo un acto libre, sino también de alguna manera, configurador de la vocación misma». OcárIZ, F., «La vocación al Opus Dei como vocación en la Iglesia», en Rodríguez, P., Ocáriz, F. e Illanes, J. L., El Opus Dei en la Iglesia. Introducción eclesiológica a la vida y al apostolado del Opus Dei, Madrid: Rialp, 1993, 135-198, aquí 137.

${ }^{9}$ Cfr. PDV, 37.

${ }^{10}$ Llamada de Dios que es previa y prioritaria (cfr. PDV, 36). 
les para permitir encontrar un sentido por el que vivir, sentido que siempre es alguien: una vida con sentido es una vida vivida para alguien. Así, la soledad experimentada por Adán encierra una profunda verdad antropológica que ilumina el fin último de la libertad al ponerla en relación con el amor, que es siempre salida de sí. En efecto, sólo el amor es motivo suficiente para poner en juego hasta el fondo la libertad. Y, a la vez, el amor no consiente una libertad vivida a medias. La lógica del amor es la de una adhesión por la que, renunciando a todo lo demás, uno se sabe agraciado, vencedor ${ }^{11}$. Las parábolas de la perla preciosa y del tesoro escondido lo ilustran con maravillosa fuerza (cfr. Mt 13,44-46).

En segundo lugar, para que una respuesta de este tipo pueda darse, se requiere tanto una percepción de que es Dios el que llama, como del contenido de la llamada. A la vez, es necesario entenderla en el contexto de la pregunta fundamental por el sentido de la propia vida, que no puede ser otro que el amor.

Por una parte, la percepción de la llamada de Dios es un acontecimiento de fe, que nos permite reconocer en determinados signos o personas la voz de Dios. Cómo se realiza dicho discernimiento, ya se ha señalado, es uno de los contenidos fundamentales de la pastoral vocacional, de la que se hablará en el segundo apartado de este estudio.

Por otra, debe percibirse el contenido de la llamada, pues la vocación nunca es atemática, sino que comporta una misión determinada. El conocimiento del «contenido» de la llamada no es necesariamente completo, ni tan sólo intelectual, pero sí debe ser suficiente para que la adhesión a él pueda ser calificada de «humana» ${ }^{12}$.

Además, la llamada debe percibirse en relación con la cuestión de la propia vida, que es la que resulta iluminada por Cristo, y puesta en relación con el amor. Esto resulta necesario porque la respuesta a la llamada de Dios se presenta ante el sujeto como la asunción de una opción irrevocable y comprome-

11 Cfr. Mounier, E., El personalismo, ahora en IDEM, El personalismo. Antología esencial, Salamanca: Sígueme, 2002, 675-773, aquí 729-730.

12 Cualquier persona familiarizada con la cuestión sabe de la importancia que en esta cuestión tienen los «modelos», como camino ordinario de conocimiento de las distintas vocaciones particulares suscitadas por Dios en el seno de su Iglesia. A la vez, no puede ignorarse la importancia de este conocimiento para suscitar el attrait, que constituye uno de los posibles signos ordinarios en los que la persona discierne la voz de Dios. Por último, es una dolorosa constatación cuánto ha condicionado negativamente la pastoral vocacional la crisis de identidad sacerdotal o de la vida religiosa. 
tedora de toda la existencia. Es decir, con unas características que exigen al hombre algo que sólo está dispuesto a dar por amor.

Finalmente, resulta imprescindible comprender que la llamada de Dios se percibe en la Iglesia, se recibe para la Iglesia y es concreción de la primera y fundamental vocación que, constituyéndonos en hijos de Dios por el bautismo, nos hace contemporáneamente miembros de una comunidad unida por profundos vínculos sobrenaturales. En la medida en que el cristiano no puede entenderse al margen de la Iglesia, sino que lo es en la medida en que es Iglesia -en esa misma medida-, toda vocación es eclesial por su misma naturaleza ${ }^{13}$.

Afirmado lo anterior, puede concretarse la mediación de la Iglesia en el planteamiento y seguimiento de la propia vocación en términos de ayuda, de discernimiento y de autentificación. De este modo, la Iglesia se presenta ante los ojos de cada hombre como el lugar propio de su diálogo vocacional, liberándolo de todo subjetivismo, a la vez que garantizando y protegiendo su carácter plenamente personal; se convierte así en la «patria» espiritual de cada vocación. De todo ello se hablará en el segundo apartado de este estudio.

\section{b) Historicidad}

El diálogo vocacional se desarrolla en la historia. Afirmación ésta que, desde el punto de vista de Dios, plantea la cuestión de la articulación entre la eternidad y la temporalidad como elementos indisociables de la llamada ${ }^{14}$. Desde el punto de vista del hombre -que es de quien se quiere hablar en este estudio-, exige tomar en consideración el carácter histórico del origen psicológico de toda vocación. Pero no sólo; también de las consecuencias que la condición histórica del hombre tiene en la comprensión del camino vocacional, tanto en su etapa de «discernimiento», como en la más importante de desarrollo a lo largo de toda la vida.

La vocación, en efecto, es algo que se descubre. Esto quiere decir, básicamente, que irrumpe como una novedad de sentido en una vida que discurría por una senda diversa. $Y$ que irrumpe en un tiempo preciso, aunque no necesaria, ni siquiera habitualmente, en un instante.

Por otra parte, el descubrimiento de la propia vocación suele venir acompañado del sentimiento de la propia indignidad, que se traduce a veces en el

${ }^{13}$ Cfr. PDV, 35.

${ }^{14}$ Cfr. OCÁRIZ, F., «La vocación al Opus Dei», 152-153. 
miedo «a no estar a la altura»: ante la desproporción entre la vida de santidad, que se entiende requiere la llamada percibida, y la vida que realmente se está viviendo; entre la madurez requerida y la que se cree tener. Como si la llamada se dirigiera a un sujeto que no podría acogerla sin morir aplastado por ella; dicho con palabras llanas: le «viene grande».

En este sentido, el lema del papa Francisco Miserando atque eligendo ofrece un marco hermenéutico que permite superar eficazmente estas dificultades. Pero es un marco que requiere ser explicado para que pueda desplegar todo su valor. Por una parte, resulta necesario tomar nota de la relación estrecha que se da entre la libertad de autoposesión y la libertad de adhesión, que no es, sin embargo, estrictamente sucesiva. Aunque ya se ha visto que la plena adhesión exige la capacidad de adherirse (autoposesión), es un dato de experiencia que la adhesión es inicialmente posible con pequeños o grandes márgenes de incoherencia. En este caso, su autenticidad no se mide por la intachabilidad moral, sino por el deseo y la lucha sincera por alcanzar el bien deseado. En este sentido, podría hablarse de una precedencia de la adhesión, que pone en movimiento con renovado vigor la siempre apasionante conquista de la libertad interior (autoposesión). Quien haya tenido experiencia o haya sido testigo de la fuerza transformadora para bien que tienen las relaciones amorosas auténticas, entenderá de modo muy intuitivo lo que se está diciendo.

Por otra parte, la mutua ayuda que, si se me permite hablar así, se prestan la libertad de autoposesión y la de adhesión, se desarrolla en el tiempo. Cada persona necesita tiempo, en primer lugar, para hacer las cuentas con sus limitaciones físicas, psicológicas y morales, y saber cómo afrontarlas. Y, posteriormente, tiempo para que las decisiones tomadas obren el resultado buscado.

En este campo, conviene no olvidar que, entre las grandes manifestaciones de la misericordia de Dios, se encuentra la de no permitir que seamos tentados por encima de nuestras propias fuerzas (cfr. 1 Cor 10,13). La «gestión» de los defectos morales (pecados) es, por ello, distinta de los físicos o psicológicos. Mientras los segundos deben ser «integrados»y, en algunos casos no impiden el seguimiento de la propia vocación, los primeros deben ser «superados» ${ }^{15}$. Entiéndase que me refiero aquí a los pecados mortales, en la medida en que éstos pueden ser habituales. La autenticidad de la vocación se mide también en este campo; al menos así lo ha hecho siempre la Iglesia, sirviendo

15 Cfr. S. Juan Pablo II, Enc. Veritatis Splendor (6-VIII-1993) 102, pero vid. también 103-105. 
tanto a la persona (a la que se le evita una situación de doble vida, a la larga insoportable, y un peligro para su alma), como a la misma comunión eclesial.

Por ello, comprender bistóricamente la respuesta a la vocación significa contar de modo agradecido con un tiempo de preparación a la respuesta plena. No es una casualidad que toda vocación particular lo tenga, ni que la respuesta se produzca a través de incorporaciones parciales a la institución a la que la persona se siente llamado. En este sentido, es particularmente importante señalar que este tiempo ha de leerse también como revelador del designio divino ${ }^{16}$. Y que dicha lectura debe hacerse a la luz de la mayor o menor capacidad de corresponder a los requisitos objetivos que comporta la vocación inicialmente percibida ${ }^{17}$.

Pero si la condición histórica del hombre es relevante para comprender su proceso de descubrimiento y de maduración, lo es también -y de modo fundamental- en su desarrollo: el acierto en la vocación, cuando ya se ha abrazado plenamente, se mide existencialmente por su vivencia dichosa hasta el final. Porque el carácter irrevocable de la respuesta exige la fidelidad al plan de Dios, que en la decisión vocacional tuvo un especial «espesor», pero que se prolonga a lo largo de toda la vida ${ }^{18}$.

Hablar, pues, de fidelidad significa sacar consecuencias del carácter dialógico de la vocación, que no se nos da como un todo cerrado ${ }^{19}$, sino que

${ }^{16}$ Por eso es extremadamente delicado (y muchas veces falso) presentar como un «fracaso» el abandono de un camino vocacional en el curso de su proceso de formación o tras alguna incorporación parcial. Como lo sería calificar directamente de «injusticia», el juicio de no idoneidad que corresponde a la autoridad competente. Si hay un periodo de la historia personal en el que con mayor claridad pueden leerse los signos de la llamada de Dios, es precisamente en el que media entre la decisión vocacional y su plena culminación.

17 Requisitos que deben verificarse a su tiempo y de modo progresivo. Vid. en lo que tiene de paradigmático para todo camino vocacional cuanto dice CONGREGACIÓN PARA EL CLERO, Ratio Fundamentalis Institutionis Sacerdotalis (8-XII-2016), 58 (en adelante: Ratio).

18 «Corren ahora tiempos en que la superficialidad facilita negar hoy lo que se entregó ayer. En la formación de los cristianos - de los futuros sacerdotes tanto como de los religiosos o de los que contraerán matrimonio- hay que favorecer el cultivo de las virtudes intelectuales. Y con ellas, también la madurez contemplativa (sentimientos, sensibilidad, voluntad) que lleva a la captación existencial profunda -que hace posibles las decisiones definitivas-. Podría hablarse -y así es exigitivamente- de la opción fundamental que caracteriza la profesión religiosa o el "sí" de la ordenación sacerdotal. Pero la evidencia subraya que -paradójicamente- son también posibles las "opciones fundamentales" superficiales, inauténticas, opciones cerradas en falso. La elección fundamental procede de la soberanía del "yo" en toda su radical intimidad y en toda su entereza. De no ser así, no estamos - pienso- ante una opción fundamental auténtica». DE LA LAMA, E., «Hacia un compromiso fundamental», ahora en IDEM, Historiológica. Estudios y ensayos, Pamplona: Eunsa, 2006, 25-55, aquí 54-55.

19 Cfr. OCÁRIZ, F., «La vocación al Opus Dei», 144-145. 
queda constitutivamente abierta a seguir escuchando las llamadas de un Dios que, «porque es fiel, no puede negarse a sí mismo» $(2 \mathrm{Tm} 2,13)^{20}$. Pero también exige el mismo ambiente para el desarrollo de la vocación que el necesario para su descubrimiento y aceptación: el caracterizado por una auténtica y genuina libertad ${ }^{21}$.

\section{El evangelio de la vocación en el contexto actual}

El evangelio de la vocación, tal y como lo anuncia la Iglesia, tiene en el hombre de boy su interlocutor concreto. Pero, ¿quién es, en último término, el hombre, el joven de boy?

Una constatación que casi parece superflua es que el hombre de boy es, en su núcleo más esencial, el hombre de siempre. Algo que se pone de manifiesto sin necesidad de recurrir de modo inmediato a cuestiones metafísicas, en la permanencia de los grandes anhelos e interrogantes, magistralmente presentados en la constitución pastoral Gaudium et Spes ${ }^{22}$.

Esta última afirmación resulta, sin embargo, problemática: ¿No hay, en efecto, muchos indicios de que precisamente el hombre de boy se caracteriza por un profundo desinterés por las grandes cuestiones? ${ }^{23}$. Ante un hombre que ya no se interroga por el sentido de la vida y que ha dejado no sólo de pensar, sino también de soñar, ¿qué posibilidades quedan para que la propuesta de la vocación, tal y como la Iglesia la realiza, tenga sentido y sea acogida por los jóvenes de boy?

${ }^{20}$ Cfr. en PDV, 70 una aplicación de estas afirmaciones al caso de la vocación sacerdotal y el modo de comprender rectamente la fidelidad a ella.

21 «Auténtica» en el sentido heideggeriano de conocedora de sus límites, pues la libertad humana nunca es absoluta. Que abrazar de modo definitivo una vocación significa asumir libremente unos compromisos que condicionan el ejercicio de la propia libertad, a veces en ámbitos muy básicos, es una afirmación obvia. Por eso, una vocación «auténticamente» abrazada, no los entiende negativamente, sino como expresiones propias del sentido último de la libertad, que nos ha sido dada para el amor. Pero esto no exime a quienes detentan la autoridad de preservar como un bien esencial la conditio libertatis de los hijos de Dios, como sustrato propio de la virtud de la obediencia.

22 Esclarecerá el sentido de esta afirmación la lectura de WojTYLA, K., «La evangelización y el hombre interior», Scripta Theologica 11 (1979) 39-57. Cfr. también Gaudium et Spes, 10.

${ }^{23}$ Desinterés, que parece ser una de las señas de identidad de la posmodernidad, caracterizada tanto por el fin de los grandes relatos (cfr. LYOTARD, J.-F., La condición postmoderna: Informe sobre el saber, Madrid: Cátedra, 1984), como por la desaparición de las grandes convicciones y de las razones «fuertes». (Cfr. VATTiMO, G., El fin de la modernidad: nibilismo y hermenéutica en la cultura posmoderna, Barcelona: Gedisa, 1987). 
Considero que la respuesta pasa por asumir no sólo la descripción que se hace de la sociedad de hoy, sino también el hecho de las frustraciones que ésta acarrea al hombre, también de boy. Porque parece claro que la posmodernidad ha tenido como consecuencia el alumbramiento de una nueva sociedad, que condiciona todas las manifestaciones de la vida del hombre. Se trata de una sociedad que algunos filósofos actuales definen como líquida, del rendimiento y ligera ${ }^{24}$.

Zygmunt Bauman habla de sociedad líquida, en sentido de «sin forma precisa» $y$, por tanto, sin tiempo para que sus estructuras, razonamientos $y$ modelos puedan consolidarse, estableciendo puntos de referencia comunes a todos. Se produce, así, una completa sensación de libertad, al desaparecer incluso la tenue coacción moral de deber enfrentarse a un pensamiento dominante en ninguna de las facetas de la vida ${ }^{25}$.

Por su parte, Byun-Chul Han considera que lo más definitorio de la sociedad actual es su preocupación por el rendimiento. Aparece, en efecto, dominada por el verbo «poder», que ha sustituido en su preponderancia al «deber». $\mathrm{Al}$ interpretar su propia grandeza en términos de rendimiento, cada persona se lanza a una carrera en la que todo lo posible debe ser realizado; incluso lo que parece imposible, podría estar al alcance de la mano con un poco de esfuerzo extra. La libertad, entendida como tener todo lo que se puede (no sólo en lo material, también en lo sentimental y en lo intelectual), es entonces el resultado del esfuerzo por aumentar nuestras casi ilimitadas capacidades de producción ${ }^{26}$.

Por último, Gilles Lipovetsky, en su obra De la ligereza ${ }^{27}$, califica de ligeros los modos actuales de afrontar todas las dimensiones de la existencia.

Sociedad, pues, líquida, de rendimiento y ligera que, habiendo producido un hombre con esas mismas características, no ha producido, sin embargo, un hombre feliz. En efecto, los tres filósofos detectan, cada uno a su modo, la «venganza» que produce este modo de pensar y de configurar la sociedad sobre las expectativas del hombre.

Así, Bauman, señala que una sociedad líquida acaba siendo una sociedad manipulada por fuerzas oscuras e inaferrables; una sociedad «aterrada». Han, por su parte, describe cómo la sociedad del rendimiento ha dado paso a la so-

\footnotetext{
${ }^{24}$ Los autores que ahora se citarán representan, a mi juicio adecuadamente, una situación actual cuyas raíces son más lejanas y profundas. Para un análisis más completo de los orígenes de cuanto aquí se describe someramente, cfr. VolPI, F., El nihilismo, Madrid: Siruela, 2007.

${ }_{25}$ Cfr. Bauman, Z., Tiempos líquidos. Vivir en una época de incertidumbre, Barcelona: Tusquets, 2007.

${ }^{26}$ Cfr. Han, B.-C., La sociedad del cansancio, $2^{\mathrm{a}}$ ed., Barcelona: Herder, 2017.

27 Cfr. Lipovetsky, G., De la ligereza: hacia una civilización de lo ligero, Barcelona: Anagrama, 2016.
} 
ciedad del cansancio, y cómo la valoración del hombre en términos de capacidades esconde un narcisismo que lo incapacita incluso para el amor, convirtiéndole en un hombre solo. Finalmente Lipovetsky insiste, casi con malignidad, en las semejanzas entre la sociedad actual e Ícaro: al igual que el personaje mitológico, ésta, a fuerza de querer subir -ligera- a lo más alto, quema siempre sus alas, y cae así, estrepitosamente, en la pesadez propia de la tierra ${ }^{28}$.

Quedándonos ahora con Lipovetsky, encontramos en sus páginas dos tipos de referencias al cristianismo: por una parte, una caracterización de éste en términos de ligereza, como el modo en que todo fenómeno religioso es vivido e interpretado por quienes han asumido consciente o inconscientemente el patrón actual. Por otra, como una respuesta arcaica (premoderna, dice él ${ }^{29}$ ) a lo que hoy se busca resolver ignorándose. Porque esto sería en último término la gran pretensión de la ligereza: sentirse bien sin mucho esfuerzo y renunciando a pensar en exceso.

Se abrirían, por lo tanto, a la luz de estos análisis, dos posibilidades para el cristianismo: o bien aprende a presentarse como un producto bipermoderno, asumiendo pacíficamente una nueva función, que se medirá por el bienestar espiritual que produce en el usuario o consumidor (eso será en último término el cristiano); o bien afronta el desafío de negar que su propuesta sea «premoderna», intentando poner de manifiesto que es, más bien, la respuesta a las aporías que se revelan en estos planteamientos actuales. La decisión que se tome condicionará de modo radical la pastoral de la Iglesia, también ante la cuestión de las vocaciones. Llegamos así al segundo punto de este estudio.

\section{PROPONER, DISCERNIR Y ACOMPAÑAR LAS VOCACIONES}

Si la teología pastoral deriva sus principios de la fe, entonces convendrá aceptar la tremenda problematicidad que para la pastoral vocacional tendría asumir la propuesta de un cristianismo ligero. En efecto, en él, nociones como

${ }^{28}$ Cfr. Bauman, Z., Tiempos líquidos, 110; Han, B.-C., La sociedad del cansancio, 67-74 y, también, IDEM, La agonía del eros, Barcelona: Tusquets, 2014. Finalmente, el uso del mito de Ícaro es un recurso literario recurrente a lo largo de toda la obra de Lipovetsky, que le sirve para recalcar cuanto ya anuncia en la introducción: «Ironía hipermoderna: en el presente es la ligereza lo que nutre el espíritu de pesadez». Lipovetsky, G., De la ligereza, 15.

29 Vid. la descripción de una religiosidad interpretada en clave de «ligereza» y que podría estar en la base también de algunas propuestas cristianas, en Lipovetsky, G., De la ligereza, 61-64. La calificación de cristianismo como fenómeno premoderno en ibid., 31-32. 
compromiso, irrevocabilidad y renuncia, por señalar tan sólo algunos, desempeñarían un papel secundario y, por supuesto, opcional. Con la dificultad añadida de su encuadramiento intelectual en una propuesta que explícita o implícitamente toma, como punto de partida y finalidad última del cristianismo, «sentirse bien desde el punto de vista religioso». No es de extrañar, por tanto, que en una reflexión que adoptase este punto de partida, la pastoral vocacional lleve necesariamente unida a un «repensamiento» del contenido y de las exigencias de cada vocación concreta, generalmente buscando disminuirlas. Porque sólo una vocación ligera puede ser asumida por un cristiano ligero $^{30}$.

Hacer derivar la pastoral de los principios de la fe significa, en cambio, dejar que la acción se ilumine por el punto de llegada. Éste viene definido tanto por la naturaleza teológica de la vocación (que es de lo que hemos hablado en el primer apartado), como por la identidad precisa de cada vocación particular (cuya presentación excede este estudio). Determinar el punto de llegada permitirá reconocer el modo de afrontar el punto de partida y los medios para ayudar al hombre de boy a recorrer la distancia entre uno y otro. Ése será el itinerario que recorrerán las reflexiones que siguen.

\section{El punto de llegada: una vocación adecuadamente asumida}

El punto de llegada de la pastoral vocacional no puede ser el «descubrimiento» del propio camino; ni siquiera ayudar a que se emprenda con generosidad y liberalidad de ánimo. Eso forma parte de la pastoral vocacional, pero no la agota. Si no se olvida que toda acción de la Iglesia es servicio al hombre, el fin no puede ser otro que ayudarle a vivir su vocación como lo que realmente es: su camino de realización y plenitud. Un planteamiento pastoral que no tenga como base la educación para la fidelidad gozosa e irrevocable es un plan-

${ }^{30}$ Nótese que el párrafo comienza en condicional, basándose en una comprensión de la teología pastoral subyacente a las enseñanzas de la Pastores dabo vobis (cfr. PDV, 57). En efecto, hay corrientes que entienden que el punto de partida de la teología pastoral es la autoconciencia de la Iglesia en cada momento histórico, verdadero lugar teológico desde el que sería legítimo repensar los contenidos de la fe. Bajo este punto de vista, la efectiva constatación de la existencia de un cristianismo ligero justificaría opciones pastorales que atenuasen los contenidos de cada vocación específica, sin presentarlas necesariamente como cambios de doctrina. Esta concepción de la teología pastoral plantea por lo menos la grave objeción histórica de ser contraria al modo en el que la Iglesia ha actuado siempre, buscando informar la sociedad y los corazones de los hombres con los principios derivados del evangelio. 
teamiento condenado al fracaso y que, desgraciadamente, dejará por el camino muchas personas desencantadas, quizás para siempre.

Se trata, en efecto, de ayudar a que la vocación asumida sea lo que defina el propio lugar en la vida. Más aún, que defina a la persona misma que, sin referirse a su vocación, no se entendería. Se debe, pues, ayudar a dar una respuesta que configure totalmente con la llamada recibida, haciéndola tan real en la propia vida, que pueda decirse de verdad: «yo soy mi vocación» ${ }^{31}$. Ésta y no otra es la finalidad de la pastoral vocacional.

\section{El punto de partida: la función «mayéutica» de la pastoral}

Difícilmente se llega a una meta así partiendo de una humanidad ligera, de un cristianismo ligero. Por eso, resulta necesario asumir que el punto de partida de la pastoral vocacional no es el hombre de boy tal y como se presenta y se vive a sí mismo, sino el hombre de siempre, que debe ser descubierto en cada uno de nuestros contemporáneos. Y por hombre de siempre entendemos el hombre redimido por Cristo y bajo la constante acción de la gracia de Dios, que es quien le da sus verdaderas posibilidades ${ }^{32}$. En efecto, la acción de la gracia y la transformación en Cristo no son ajenas ni a la historicidad del hombre ni a la misión de la Iglesia. «Sacar» al hombre de siempre y cooperar a que el hombre nuevo sea engendrado, son dos facetas de la misma misión pastoral, basada en la profunda relación entre naturaleza y gracia. Hasta qué punto esta tarea exige la implicación personal de los cristianos, queda patente -a través del recurso a un lenguaje estrictamente mayéutico- en Gal 4,19.

Para que el hombre de boy, el joven de hoy, se atreva a reconocerse en toda la seriedad de su existencia, es imprescindible, pues, animarle a pensar, a que-

${ }^{31}$ Unas palabras de san Josemaría, que se mueven en el mismo plano antropológico y existencial en el que se mueven estas páginas, sintetizan, a mi juicio de modo magistral, el punto de llegada al que nos referimos: «La vocación nos lleva -sin darnos cuenta- a tomar una posición en la vida, que mantendremos con ilusión y alegría hasta en el trance de la muerte. Es un fenómeno que comunica al trabajo un sentido de misión, que ennoblece y da valor a nuestra existencia. Jesús se mete con un acto de autoridad en el alma, en la tuya, en la mía: ésa es la llamada». S. JoSemaría Escrivá de Balaguer, Carta (9-I-1932) 92, cit. en VÁzQuez de Prada, A., El Fundador del Opus Dei. I. Señor, que vea, Madrid: Rialp, 1997, 294. El texto, más largo que el aquí citado, es riquísimo y ha servido para ilustrar aspectos esenciales de la teología de la vocación (cfr. OCÁRIZ, F., «La vocación al Opus Dei», 148-153).

32 Cfr. Veritatis Splendor, 103. 
rer, a soñar. En definitiva, hay que ilusionarle con la grandeza de su propia vida $^{33}$. Por utilizar un verbo de raigambre paulina: hay que despertarle.

Enseñar «a vivir», despertar de los efectos anestesiadores de la cultura dominante, es el punto de partida de toda pastoral vocacional que, por ello, se inserta con naturalidad en el conjunto de la pastoral juvenil ${ }^{34}$. Porque, no lo olvidemos, la pastoral es, esencialmente «acción». Que muchos jóvenes se «despiertan» porque «han tocado fondo» o han tenido experiencias de sufrimiento, es un dato de experiencia. Pero la pastoral no consiste en «esperar» a que la vida despierte a los jóvenes a base de sacudidas, sino en encontrar caminos para que esto suceda en el curso de su vida ordinaria, deseablemente buena y sin grandes traumas. Cómo lograrlo, es la pregunta por los medios.

\section{Medios: los imprescindibles}

Una película que marcó profundamente a los que empezábamos a ser jóvenes a finales de los años ochenta del siglo pasado -El club de los poetas muertos (Peter Weir, 1989)- prácticamente comenzaba con unas palabras de Henry David Thoreau:

«Fui a los bosques porque quería vivir deliberadamente; enfrentar sólo los hechos esenciales de la vida y ver si podía aprender lo que ella tenía que enseñar, para no darme cuenta, en el momento de morir, que no había vivido» ${ }^{35}$.

Estas frases de Thoreau muestran la necesidad de un ambiente (los bosques) y de un lugar (la propia interioridad, como lugar de reflexión profunda sobre uno mismo), para que el «despertar»y sus consecuencias (una vida auténtica) sucedan. «Ambiente»y «descubrimiento de la interioridad» constituyen, pues, los dos primeros medios necesarios para toda pastoral vocacional.

33 Vid. al respecto, Francisco, Vigilia de oración con los jóvenes en Cracovia (30-VII-2016). Una pastoral vocacional que no parte de una «ilusión» por una vida grande, está condenada de antemano al fracaso.

${ }^{34}$ Cfr. Francisco, Vigilia de oración con los jóvenes en Cracovia (30-VII-2016). Sobre los jóvenes «jubilados» y sin esperanza, cfr. IDEM, Ceremonia de acogida de los jóvenes en Cracovia (28-VII-2016).

35 «I went to the woods because I wished to live deliberately, to front only the essential facts of life, and see if I could not learn what it had to teach, and not, when I came to die, discover that I had not lived». Thoreau, H. D., Walden, 1854. 


\section{a) Ambiente}

Hacer de las parroquias, o de cualquier otro escenario en el que la Iglesia desarrolla su pastoral juvenil, un ambiente donde pueda «respirarse el evangelio» y pueda aprenderse casi por contagio, constituye el primero de los desafíos. Para ello, y sin la mínima pretensión de exhaustividad, señalo tres elementos que deberían tenerse en cuenta:

El primero es que sea un ambiente en el que pueda percibirse un verdadero interés por ellos (por los jóvenes). No es un requisito tan sólo psicológi$\mathrm{co}^{36}$, sino también teológico: el hombre debe ser amado por sí mismo y el objeto del interés es el bien de la persona, que precede a cualquier otro tipo de pretensión o planteamiento en clave de utilidad ${ }^{37}$. Pero este interés debe manifestarse también en la capacidad de abrirles a otros intereses; de enseñarles a gustar tantas manifestaciones de la cultura que hacen al hombre «más humano»y consiguientemente, más «abierto a Dios» y a escuchar su voz ${ }^{38}$.

En segundo lugar, en ese ambiente, la presentación del evangelio en su integridad debe hacerse en términos de esperanza antes que de exigencia. Se trata de una esperanza basada en la confianza en la acción de la gracia, que necesita de la apertura del corazón y del tiempo, como tantas veces repite el papa Francisco en sus encuentros con los jóvenes ${ }^{39}$.

Finalmente, debe ser un ambiente presidido por un clima de auténtica libertad, que ha de ser experimentada realmente por los jóvenes. En efecto, la falta de libertad -también la falta de percepción de la libertad, aunque sea una percepción distorsionada ${ }^{40}-$ falsifica por completo cualquier proceso de creci-

${ }^{36}$ Cfr. Documento preparatorio, III.1. El interés real por «las cosas de los jóvenes», está en la base de la pedagogía de san Juan Bosco, maravillosamente expresada en su carta del 10-V-1844.

37 También en la pastoral juvenil puede darse una «cultura del descarte»: como de hecho ocurre cada vez que se ve a los jóvenes «en potencia» y se les acepta o rechaza en la medida en que acaban cumpliendo las expectativas de quienes les tratan (ser catequistas, abrazar determinada vocación, etc.).

${ }^{38}$ Porque una pastoral juvenil o vocacional planteada tan sólo en términos de diversión no arranca al joven de su ligereza cultural, con el consiguiente riesgo de que la pregunta por la vocación o la respuesta inicial se deba a razones excesivamente humanas y su desarrollo quede gravemente comprometido por la ausencia de «sujeto». En este sentido, cuidar la dimensión humana de la formación resulta esencial. Vid., como ilustración de cuanto digo LORDA, J. L., Humanismo. Los bienes invisibles, Madrid: Rialp, 2009 e IDEM, Humanismo II. Tareas del espíritu, Madrid: Rialp, 2010.

39 Cfr., por ejemplo, Francisco, Ceremonia de acogida de los jóvenes en Cracovia (28-VII-2016).

40 Aquí vale, y con más razón por ser una cuestión mucho más vital, lo de la mujer del César, que no sólo tiene que ser honrada, sino que debe también parecerlo. Que los ambientes pastorales que se ofrecen a los jóvenes sean percibidos por ellos como ambientes de libertad, debería ser objetivo primero de quienes tienen la misión de dirigirlos y orientarlos. 
miento, y acaba por esterilizar cualquier tipo de acción pastoral. Sólo la percepción y la experiencia de la libertad, entendida como inmunidad a la coacción, hace posible que un joven abra la puerta de su corazón y se deje ayudar en algo tan personal e íntimo como su propia formación personal.

\section{b) Descubrimiento de la interioridad}

Los «bosques» eran el ambiente propicio para que Thoreau lograra pensar profundamente sobre sí mismo. Un ambiente para descubrir la propia interioridad, única instancia desde la que poder vivir de modo auténtico. Se entiende, pues, que enseñar a vivir desde dentro, orientar el recorrido hacia un propio interior que debe ser conocido, constituya uno de los medios imprescindibles de la pastoral vocacional. Quizás la vocación puede ser descubierta e incluso iniciada desde otras instancias más superficiales de la persona, pero sólo desde su mismo centro puede ser abrazada de modo irrevocable.

Ahora bien, ¿cómo acompañar a los jóvenes en este viaje a la interioridad? En primer lugar, siendo conscientes de los «fenómenos» propios del mundo interior y orientando a cada persona en la correcta «gestión» de éstos. El descubrimiento (casi propiamente podría hablarse de «nacimiento») de la interioridad o intimidad ocurre generalmente en la adolescencia y tiene tres manifestaciones principales: la conciencia de un proprium que sólo debe ser manifestado a quien uno quiere (de ahí la aparición de confidentes elegidos -los amigos- en un lugar que hasta entonces correspondía a los padres); la necesidad de manifestarse como irrepetible (con la consiguiente exigencia de hacer propios los valores recibidos o contestarlos con vehemencia); y la conciencia de la temporalidad (inicialmente hacia el futuro, en forma de sueños y proyectos cada vez más realistas; en un momento posterior, en la toma de conciencia del pasado, de la propia historia, y de su carácter a la vez revelador y condicionante).

A la luz de estas grandes manifestaciones de la interioridad, se entiende la importancia fundamental de encontrar en quien confiar y de enseñar a confiar en quien se hace digno de ello. No por casualidad es en el ambiente que acabo de describir donde el joven descubre a las primeras personas a quienes confiar su inquietud vocacional. Éstos son, pues, los primeros acompañadores de las vocaciones, en la medida en que la conciencia del joven ha decidido abrirse a ellos. Cumplen así una auténtica misión eclesial, sin necesidad de 
haber recibido para ello más encargo que el recibido por su condición bautismal de contribuir a la edificación del cuerpo místico de Cristo ${ }^{41}$. La dirección espiritual da forma y concreta, de un modo especialmente fecundo, la ayuda que la Iglesia ofrece a cada persona en el descubrimiento de su vocación $^{42}$. Hasta qué punto el genuino interés por la persona, la discreción y la delicadeza (muchas veces en forma de paciencia) son actitudes que inspiran confianza y deben caracterizar esta labor de acompañamiento, no resulta necesario explicarlo ${ }^{43}$.

La apertura de la intimidad permitirá acompañar al joven sugiriéndole los medios necesarios para que pueda crecer y convertir en realizables sus opciones y sueños. El acompañamiento personal aparece así como expresión elocuente de servicio evangélico a cada persona, entendiéndose fácilmente su profunda raigambre en la pastoral de la Iglesia. Pero también es esencial entender que no es el medio principal. En efecto, es secundario respecto a la necesidad de escuchar la voz de Jesucristo, de entrar en el camino de la oración, de tratarle personalmente. Sólo Él manifiesta al hombre «la sublimidad de su vocación». Por eso, quien acompaña a una persona en su vida espiritual está llamado a ser, antes que nada, maestro de oración.

Pero hacer oración es, a la vez, fácil y difícil. Por ello, quien quiera enseñar a hacer oración debe ser consciente de esta aparente contradicción y no resolverla por el sencillo expediente de borrar alguno de estos dos polos. Borra la «facilidad» quien embarca a la persona a través de métodos excesivamente prefijados o le enfrenta a textos que quedan inicialmente lejos de sus capacidades. Borra la «dificultad» quien consiente una oración que se prolongue

${ }^{41}$ La convicción de que la pastoral vocacional es propia de toda la Iglesia y de que en ella deben participar todos los cristianos es una afirmación que se encuentra literalmente en el Concilio Vaticano II (cfr. Decr. Presbyterorum Ordinis, 11) y que ha sido posteriormente repetida por los sucesivos pontífices (cfr. PDV, 41). Se entiende que el planteamiento se apoya en una eclesiología renovada, en la que la colaboración de los fieles a la pastoral de la Iglesia no discurre ni única ni principalmente a través de los específicos encargos que la Jerarquía puede y debe encomendar en razón de su función propia.

${ }^{42}$ Cfr. PDV, 44. Nunca se insistirá suficientemente en el exquisito respeto con que debe conducirse quien acompaña en estas cuestiones, sabiéndose testigo privilegiado de cuanto Dios suscita en el corazón de la persona. Si la respuesta configura la llamada, la respuesta debe ser a lo que se entiende que Dios pide, no -huelga decirlo- a lo que al acompañante le gustaría. Cfr. al respecto, DE LA LAMA, E., «Reflexión antropológica sobre la dirección espiritual», ahora en IDEM, Historiológica, 379-397, sobre todo, 388-397.

${ }^{43}$ Pero se leerá con fruto al respecto, EsPA, F., Cuenta conmigo. El acompañamiento espiritual, Madrid: Palabra, 2017, 35-45. 
en el trascurso de la vida a través de una banalización del trato con Dios (en la medida que se le «cuentan» banalidades) o busque la perseverancia en ésta a través de un recurso continuo a la parte sentimental y emotiva (que, por otra parte, cada vez necesita «más» para conmoverse) $)^{44}$.

Enseñar a escuchar a Jesucristo; ése es el gran desafío de toda la acción pastoral de la Iglesia y, desde luego, de la pastoral vocacional, puesto que es Él quien llama y quien debe ser respondido, quien sale fiador de la fecundidad de la respuesta generosa ${ }^{45}$.

\section{c) Discernimiento: el punto de inflexión}

«Ambiente»y «lugar» son necesarios para: para tomar una decisión de modo que pueda ser acertada y conforme a la naturaleza de la llamada (respuesta de amor irrevocable). En este contexto, el «discernimiento» ${ }^{46}$ tiene, entre los medios, razón de fin. Se convierte en el instrumento adecuado para que la persona descubra su propio camino y pueda abrazarlo.

En esta labor no todos en la Iglesia desempeñan la misma función ni tienen el mismo peso. Se entiende que una palabra especial corresponde a quienes «representan» a la Iglesia en cada camino vocacional concreto: el obispo y el rector del seminario en las vocaciones sacerdotales; el superior en las religiosas; quien represente a la institución concreta en cada caso.

No teniendo el mismo papel -pues es indudable que un cierto discernimiento se da también en las formas de acompañamiento de las que se hablaba antes-, todos sin embargo se mueven en los mismos parámetros tanto subjetivos como objetivos: el subjetivo de buscar siempre el bien de la persona, a la que la Iglesia reconoce (no otorga) el derecho fundamental de seguir su propio camino, y el objetivo, que lleva a valorar la idoneidad para la vocación que se propone seguir. En efecto, en la labor de discernimiento, los criterios de

${ }^{44}$ De hecho, el Catecismo de la Iglesia Católica, recordando la vocación universal a la oración (cfr. 2566-2567), no duda de calificarla de «combate» (cfr. 2725-2758).

45 Por eso, antes (deseablemente) o después (en cualquier caso) resulta imprescindible que la persona sea consciente y asuma como tal que la llamada proviene de Dios y no de cualquier otra instancia por prestigiosa y autorizada que pueda aparecer ante su propia conciencia. Cfr., al respecto, SaUvage, M, «Vocation. II», 1131 .

46 El discernimiento vocacional viene definido como: «el proceso por el cual la persona llega a realizar, en el diálogo con el Señor y escuchando la voz del Espíritu, las elecciones fundamentales, empezando por la del estado de vida». Documento preparatorio, II, 2. Sobre el discernimiento, cfr. RUPNIK, M. I., El discernimiento, Burgos: Monte Carmelo, 2015. 
idoneidad desempeñan un papel objetivante en cuyo cumplimiento, o no, tanto la Iglesia como el sujeto pueden escuchar la voz de Dios ${ }^{47}$.

Pero, sobre todo, hay que recordar que discernimiento es, antes que otra cosa, discernimiento personal; y así lo enseña y promueve la Iglesia ${ }^{48}$. De ahí la importancia del clima de libertad, y de educar en una libertad interior que ayude a superar los condicionantes internos y externos que a veces paralizan -impidiéndola- la decisión vocacional.

\section{Recorrido: aprender (y enseñar) a «gestionar» los tiempos}

La importancia que tiene el carácter histórico del hombre en la comprensión de la vocación exige reflexionar sobre la incidencia de la temporalidad en la acción pastoral de la Iglesia en este campo.

En este sentido, habría que comenzar por afirmar que lo que el Papa quiere que sea característico de toda la acción evangelizadora de la Iglesia ( $\ll$ generar procesos» más que «ocupar espacios» ${ }^{49}$ ) es algo ya presente en todo acceso a una vocación particular en la Iglesia. Se trata de un proceso formativo que se traduce también en el distinto valor canónico (temporal, definitivo) de los distintos pasos hacia la plena asunción de la llamada. La cuestión no es, por tanto, generar un proceso (que ya existe), sino reflexionar sobre cómo favorecer que cumpla su función. Una vez más, aquí sólo pueden darse unas orientaciones generales.

La primera se refiere al modo de recorrer el tiempo que media entre la decisión y su culminación, periodo que -de un modo u otro- suele estar marcado por una intensa formación inicial. En este campo, la indicación ofrecida por la nueva Ratio sobre la formación sacerdotal puede ser universalizada a cualquier camino vocacional particular. Ésta lo presenta, por una parte, como un tiempo que debe ser vivido «en primera persona», es decir, huyendo de toda impresión de «cinta transportadora» que cuasi automáticamente termina

${ }^{47}$ Los criterios de idoneidad para el discernimiento adecuado de la autenticidad de las distintas vocaciones, así como la obligación de realizar el juicio de discernimiento e idoneidad conforme a dichos criterios, ha estado siempre presente en la tradición canónica. Lógicamente, el juicio de idoneidad debe contar con el tiempo. Así, el mismo Código de Derecho Canónico establece requisitos diversos para la admisión al seminario mayor (c. $241 \$ 1$ ) que para la ordenación, por ejemplo (c. 1029).

${ }^{48}$ Cfr. Documento preparatorio, II, 2, elegir.

49 Cfr. Francisco, Ex. ap. Evangelii gaudium (24-XI-2013), 222-225. 
en el momento de la asunción plena de la propia vocación. Por otra parte, lo entiende en términos de potenciación de la propia personalidad, no de una suerte de «homologación» igualitaria ${ }^{50}$.

La segunda tiene que ver con la cuestión del tiempo más oportuno, tanto para el planteamiento de la vocación, como para los sucesivos pasos intermedios entre la decisión primera y su culminación. Quizás lo más sensato sea afirmar que no es posible dar reglas generales. De nuevo, el empeño de la Ratio para la formación sacerdotal en insistir en la personalización de los ritmos del proceso es universalizable.

Con todo, en el caso de la propuesta vocacional primera, se pueden señalar tres elementos que debería tener presente quien realiza la propuesta a la hora de formarse el juicio de prudencia: que la persona debe estar capacitada mínimamente para afrontar la cuestión y que, por tanto, tiene ya una cierta «vida interior»; que la llamada va a ser probablemente respondida en términos de cambio de vida, de lucha auténtica por acercarse más a Dios y a vivir con más coherencia; y, finalmente -teniendo en cuenta que una propuesta vocacional es siempre una cierta anticipación a algo que en un contexto cristiano viene normalmente de suyo-, que se den los motivos para pensar que «no proponer» iría en detrimento del bien de la persona ${ }^{51}$.

Por último, la gestión de los tiempos tiene que ver con la cuestión de la idoneidad, que no es la misma para empezar un camino que para culminarlo. Como de esto ya se ha hablado anteriormente no resulta necesario insistir.

«Cristo... manifiesta plenamente el hombre al propio hombre y le descubre la sublimidad de su vocación» ${ }^{52}$. Las conocidísimas palabras de la Gaudium et Spes nos han acompañado a lo largo de este estudio. Sólo a la luz de Cristo, en diálogo con Él, puede el hombre conocerse en toda su grandeza.

\footnotetext{
50 Cfr. Ratio, 93.

51 La expresión clásica de «provocar crisis vocacionales» está semánticamente emparentada con la de «provocar un parto», algo que sólo se hace cuando hay una causa grave para el niño o la madre (provocarlo por comodidad del médico se consideraría una falta de ética profesional). Por eso, no parece un razonamiento adecuado, al menos de modo universal, el anticipar la cuestión vocacional, provocándola, tan sólo por el miedo a un posible (aunque nunca cierto) abandono de los jóvenes del ambiente cristiano en el que debería surgir, quizás en un momento más tardío, la pregunta por el propio camino.

52 Gaudium et Spes, 22.
} 
Grandeza de origen, fundamento de su dignidad inalienable y del carácter insuplantable de su propia libertad. Pero también grandeza de destino, que es destino de gloria, en el que se consumará para siempre esa relación de amor que, en forma de historia personal de salvación, es cada vida, cada vocación.

Este diálogo de salvación y de plenitud acontece en la Iglesia como en su lugar propio, y la pastoral vocacional está al servicio del hombre en este diálogo. Busca ayudarle a dar una respuesta de amor, fiel e irrevocable en los términos propios de su condición, siempre envuelta en debilidad y pecado. Para ello es consciente de su deber de cooperar a la liberación del hombre de tantas ataduras (morales, a veces, culturales otras), que le impiden reconocerse en su grandeza de origen y de destino y de realizarse -como protagonista de su propia vida- en fidelidad a su propio ser.

En un pontificado en el que continuamente se nos exhorta a la «conversión pastoral» ${ }^{53}$, se enmarcará la reflexión del próximo Sínodo de los obispos; es el mismo marco con el que se han querido escribir estas páginas.

53 «Espero que todas las comunidades procuren poner los medios necesarios para avanzar en el camino de una conversión pastoral y misionera, que no puede dejar las cosas como están». Evangelii gaudium, 25. 


\section{Bibliografía}

Bauman, Z., Tiempos líquidos. Vivir en una época de incertidumbre, Barcelona: Tusquets, 2007.

De la Lama, E., La vocación sacerdotal. Cien años de clarificación, Madrid: Palabra, 1994.

DE la LaMA, E., «Hacia un compromiso fundamental», en IDEM, Historiológica. Estudios y ensayos, Pamplona: Eunsa, 2006, 25-55.

DE LA LAMA, E., «Reflexión antropológica sobre la dirección espiritual», en IDEM, Historiológica. Estudios y ensayos, Pamplona: Eunsa, 2006, 379-397.

EsPa, F., Cuenta conmigo. El acompañamiento espiritual, Madrid: Palabra, 2017.

HaN, B.-C., La sociedad del cansancio, $2^{\mathrm{a}}$ ed., Barcelona: Herder, 2017.

HAN, B.-C., La agonía del eros, Barcelona: Herder, 2014.

Illanes, J. L., Tratado de teología espiritual, Pamplona: Eunsa, 2007.

IZARD, R., «L'évolution de la notion de vocation dans l'histoire», Vocation 255 (1971) 299-319.

Josemaría Escrivá de BALAguer, Carta (9-I-1932).

LÉGASSE, S., «Vocation. I. Écriture Sainte», en Dictionnaire de Spiritualitè 16, 1081-1092.

Lipovetsky, G., De la ligereza: hacia una civilización de lo ligero, Barcelona: Anagrama, 2016.

LORDA, J. L., Humanismo. Los bienes invisibles, Madrid: Rialp, 2009.

LORDA, J. L., Humanismo II. Tareas del espiritu, Madrid: Rialp, 2010.

LYOTARD, J.-F., La condición postmoderna: Informe sobre el saber, Madrid: Cátedra, 1984.

Martini, C. M. y VAnhoye, A., La llamada en la Biblia, Madrid: Atenas, 1983.

Mounier, E., «El personalismo», en IDEM, El personalismo. Antología esencial, Salamanca: Sígueme, 2002, 675-773.

OCÁRIZ, F., «La vocación al Opus Dei como vocación en la Iglesia», en RoDRígueZ, P., OCÁRIZ, F. e Illanes, J. L., El Opus Dei en la Iglesia. Introducción eclesiológica a la vida y al apostolado del Opus Dei, Madrid: Rialp, 1993, 135-198.

RatZINGER, J., Introducción al cristianismo, Salamanca: Sígueme, 1987.

RuPNIK, M. I., El discernimiento, Burgos: Monte Carmelo, 2015.

SAUVAGE, M., «Vocation. II. Des vocations particulières: sacerdoce et vie consacrée», en Dictionnaire de Spiritualitè 16, 1092-1158. 
Thoreau, H. D., Walden, 1854.

VATTIMO, G., El fin de la modernidad: nibilismo y hermenéutica en la cultura posmoderna, Barcelona: Gedisa, 1987.

VÁzquez de Prada, A., El Fundador del Opus Dei. I. Señor, que vea, Madrid: Rialp, 1997.

VolPI, F., El nibilismo, Madrid: Siruela, 2007.

WojTYLA, K., «La evangelización y el hombre interior», Scripta Theologica 11 (1979) 39-57. 
